

\section{Geografia e ensino de cidades: a percepção espacial dos alunos do ensino médio sobre o planejamento urbano de Goiânia/Brasil}

Geography and Civic Education: the Spatial Perception of High School Students about the Urban Planning of Goiânia/Brazil

Geografía y enseñanza de ciudades: la percepción espacial de los alumnos de la enseñanza media sobre la planeación urbana de Goiânia/Brasil

Denis Richter

Lana de Souza Cavalcanti*

\section{Resumo}

O crescimento das cidades, sobretudo nessas primeiras décadas do séc. XXI, tem acarretado em mudanças que interferem diretamente no cotidiano dos indivíduos, por exemplo, com a construção e alteração de ruas, praças, calçadas, parques, equipamentos e mobiliários urbanos. Diante desta situação reconhece-se a importância de formar nos citadinos uma análise ou uma leitura mais criteriosa sobre a organização do espaço urbano, a transformação dos diferentes lugares e proposições de mudanças necessárias que visam melhorar o planejamento da cidade. Nesse sentido, estamos desenvolvendo uma pesquisa que objetiva analisar a percepção espacial de 401 alunos do $3^{\circ}$ ano do Ensino Médio sobre o planejamento urbano da cidade, a partir de suas práticas cotidianas nas áreas de entorno de seis escolas públicas localizadas na cidade de Goiânia/Brasil.

\section{Palavras-chave}

ensino de Geografia; cidades; planejamento urbano; percepção espacial

\footnotetext{
Profesor Universidad Federal de Goias

** Profesora Tiutlar de la Universidad Federal de Goiás
} 
Geografia e ensino de cidades: a percepção espacial dos alunos do ensino médio sobre o planejamento urbano de Goiânia/Brasil

Denis Richter / Lana de Souza Cavalcanti /

\section{Abstract}

The growth of cities, especially during the first decades of the $21^{\text {st }}$ Century, have brought about changes that directly interfere with the daily life of individuals, such as with the construction and alteration of streets, squares, roads, parks, equipment and street furniture. In the face of this situation, we acknowledge the importance of educating citizens in a more rigorous analysis or reading of the organization of urban space, the transformation of the different places and proposals of necessary changes that aim to improve the planning of cities. In this sense, we are conducting an investigation that aims to analyze the spatial perception of 401 high school seniors on the urban planning of the city, based on their daily practices in the surrounding areas of six public schools located in Goiânia, Brazil.

\section{Keywords}

Teaching of geography; cities; urban planning; spatial perception

\section{Resumen}

El crecimiento de las ciudades, sobre todo en esas primeras décadas del siglo XXI, ha acarreado cambios que interfieren directamente en la cotidianidad de los individuos, por ejemplo, con la construcción y alteración de las calles, plazas, calzadas, parques, equipos y mobiliarios urbanos. Frente a esta situación, se reconoce la importancia de formar en los citadinos un análisis o una lectura más rigurosa sobre la organización del espacio urbano, la transformación de los diferentes lugares y propuestas de cambios necesarios que tienen como objetivo mejorar la planeación de la ciudad. En ese sentido, estamos llevando a cabo una investigación que tiene como objetivo analizar la percepción espacial de 401 alumnos del 3er año de secundaria sobre la planeación urbana de la ciudad, a partir de sus prácticas cotidianas en las áreas de entorno de seis escuelas públicas localizadas en la ciudad de Goiânia/Brasil.

\section{Palabras clave}

Enseñanza de la geografía; ciudades; planeamiento urbano; percepción espacial 


\section{Introdução}

A cidade de Goiânia, capital do estado de Goiás/Brasil, passou nas últimas décadas por um significativo aumento populacional. A partir do recorte temporal da segunda metade do século XX é possível destacar algumas mudanças nas dimensões dessa cidade, seja por seus números absolutos em habitantes, seja pela expansão urbana ou pelos problemas e desafios que acompanharam esse processo de crescimento.

Em 1950, por exemplo, Goiânia possuía uma população de 53.389 habitantes e passados 60 anos sua população atingiu, em 2010, o número de 1.301.892 habitantes (Instituto Brasileiro de Geografia e Estatística, 2010). Essa situação permitiu que Goiânia se transformasse em uma metrópole regional, já que, além do aumento da população, ocorreu um forte incremento na oferta de serviços, empregos e atividades econômicas presentes nesta capital.

Por outro lado, esse crescimento populacional desencadeou um processo de expansão urbana que nem sempre atendeu todas as demandas de seus habitantes, criando contextos de falta de infraestrutura para a mobilidade, equipamentos e mobiliários urbanos nos diversos espaços da cidade. Podemos observar que a velocidade deste ritmo de crescimento não foi acompanhada por políticas públicas que permitissem que todas as áreas ou bairros fossem contemplados com um planejamento urbano eficiente (Arrais, 2006). De certa forma, Goiânia possui uma desigualdade na distribuição de sua infraestrutura urbana, por exemplo, as regiões centrais ou consideradas mais valorizadas recebem maior atenção por parte da prefeitura, enquanto que áreas mais populares ou de menor concentração de renda carecem de inúmeros serviços públicos ou de equipamentos urbanos que permitam aos seus moradores ter uma melhor qualidade de vida. Entendemos que esta concepção de produção do espaço urbano acaba por limitar o direito à cidade.

Neste sentido, para compreender melhor a cidade, torna-se fundamental considerar outros elementos que podem ser indicados pela própria população, a partir da observação do espaço do entorno ou dos percursos mais comuns para os habitantes por revelarem contextos sensíveis para a vida nas cidades, a exemplo de ambientes de convivência coletiva, como as escolas, as praças, as ruas, os bairros, entre outros.

Essa situação indica que o desenvolvimento de estudos que visem conhecer e analisar a relação dos indivíduos com a vivência nos espaços urbanos é pertinente para melhorar a qualidade de vida dos citadinos. Assim, um modo de estudar essa relação é por meio da percepção espacial. Para Lynch (2006), essa perspectiva não se caracteriza como abrangente ou totalizadora, esse autor reconhece que a percepção é parcial e fragmentada, já que parte, muitas vezes, de uma leitura individual sobre um determinado espaço e que nela diferentes contextos podem ser empregados. Contudo, essa concepção de Lynch não representa um descrédito para o estudo da percepção, pelo contrário, caracteriza o foco e a especificidade dessa abordagem.

É importante destacar que a percepção possibilita, também, a identificação de elementos ou contextos tanto individuais como coletivos, ou seja, características que são perceptíveis para um determinado grupo social ou para um indivíduo. Isso depende, em muitos casos, do contexto, meio social ou uso que se faz do espaço que é analisado. Lynch (2006), em seu livro A imagem da cidade, reconhece que a cidade não é construída para um único habitante, mas para um coletivo, em que as particularidades e as individualidades são postas de lado para a constituição de um espaço plural. Por isso, uma cidade é composta por diversos elementos e objetos que possuem diferentes intencionalidades para seus moradores.

Claval (2002) contribui com esse debate ao dizer que por mais que os espaços estejam materializados, construídos, organizados ou pensados, muitas vezes, sob a ótica da padronização, a interpretação que os indivíduos fazem desses lugares não é a mesma. A leitura espacial que se produz dos espaços pode ser diversa. Nesse sentido, considera-se fundamental a construção de um olhar mais atento às particularidades que podem evidenciar questões relevantes para pensar amplamente o espaço.

Do mesmo modo, Lefebvre (2001) destaca que a cidade contemporânea e conectada com o atual modo de produção capitalista se organiza a partir de uma estratégia global, como propósito de atender às demandas exigidas ou que estão em voga por esse sistema. Consequentemente, o que ocorre é a imposição desses modelos ou estruturas para todos os indivíduos, sem considerar, na maioria das vezes, as especificidades dos lugares. Essa análise de Lefebvre contribui para valorizar o desenvolvimento de uma leitura mais crítica por parte dos indivíduos para seus caminhos percorridos cotidianamente - como sujeitos que observam, pensam e agem sobre o espaço urbano. É comum que as pessoas se acostumem com a paisagem vivenciada e, por conseguinte, tenham dificuldades de identificar os problemas ou desafios que precisam ser superados. Para esse autor, superar esse contexto pode representar a conquista do direito do morador urbano à cidadania. A partir de um conhecimento mais amplo e crítico sobre o espaço mais próximo, e na sua relação com o contexto local-global, espera-se que os indivíduos possam refletir e propor soluções.

\section{A pesquisa "Percepção Espacial e Planejamento Urbano"}

Diante desse contexto, estamos desenvolvendo uma pesquisa com o objetivo de analisar a percepção espacial dos alunos dos $3^{\circ}$ anos do Ensino Médio sobre o planejamento urbano da cidade, a partir de suas 
práticas cotidianas (mobilidade espacial, percursos na cidade, usos da infraestrutura urbana), nas áreas do entorno de seis escolas localizadas na cidade de Goiânia/Brasil.

A pesquisa intitulada "A percepção espacial dos estudantes do Ensino Médio na área do entorno de escolas em Goiânia/Brasil e em Los Angeles/ EUA: uma análise do espaço urbano" foi aprovada pelo Conselho Nacional de Desenvolvimento Científico e Tecnológico (CNPq) em dezembro de 2013 e suas atividades tiveram o início em janeiro de 2014 a partir dos encontros/reuniões semanais da equipe, formada por professores e alunos dos cursos de graduação e Pós-Graduação em Geografia da Universidade Federal de Goiás (UFG), nas dependências do Laboratório de Ensino e Pesquisa em Educação Geográfica (LEPEG).

Inicialmente, este projeto tinha como recorte espacial duas cidades Goiânia e Los Angeles - na perspectiva de fazer uma análise comparativa dos resultados de cada espaço urbano. Contudo, por falta de financiamento, a equipe responsável pelo estudo nos Estados Unidos não pode desenvolver a pesquisa em Los Angeles, impossibilitando o processo de análise dos resultados convergentes e divergentes em cada cidade. Por outro lado, mesmo tendo somente a cidade de Goiânia como campo de análise, esse estudo nos possibilitou identificar as demandas e, principalmente, as percepções que os jovens estudantes possuem sobre o planejamento urbano a partir de suas práticas cotidianas no trajeto casa-escola.

Desde então foi possível realizar o trabalho de levantamento bibliográfico, bem como os estudos relativos aos textos selecionados, a busca por dados secundários para a seleção das escolas participantes desse estudo em Goiânia (que totalizaram seis escolas, com um universo de 401 alunos do $3^{\circ}$ ano do Ensino Médio), a construção dos instrumentos desta pesquisa (questionário, aula de intervenção, atividades de mapas mentais e de percepção espacial), tabulação e quantificação do questionário e da atividade de percepção espacial, análise das aulas de Geografia, construção de gráficos e espacialização dos dados do questionário e sua respectiva análise e construção de gráficos da atividade de percepção espacial. Nossa expectativa é que, com a análise de todos esses materiais, teremos condições de compreender a percepção espacial dos estudantes do Ensino Médio no que diz respeito ao planejamento urbano nas áreas de entorno de suas escolas.

Quanto às características dos bairros onde se localizam as escolas, utilizamos os seguintes critérios como seleção, a saber: $\geq 4,5 \%$ da população do bairro ser de baixa renda (viver abaixo da linha de pobreza); $\leq 50 \%$ da população do bairro possuir nível de escolaridade abaixo do ensino médio; $\geq 50 \%$ do solo urbano do bairro deve ter uso residencial; e apresentar densidade demográfica $\leq 4.618 \mathrm{hab} / \mathrm{km} 2$ (índice médio de Goiânia).

Assim, tendo por base esses itens foi possível selecionar seis escolas na cidade de Goiânia que atuam no Ensino Médio e que totalizou um universo de 401 estudantes, como pode-se observar no mapa a seguir (Figura 01):

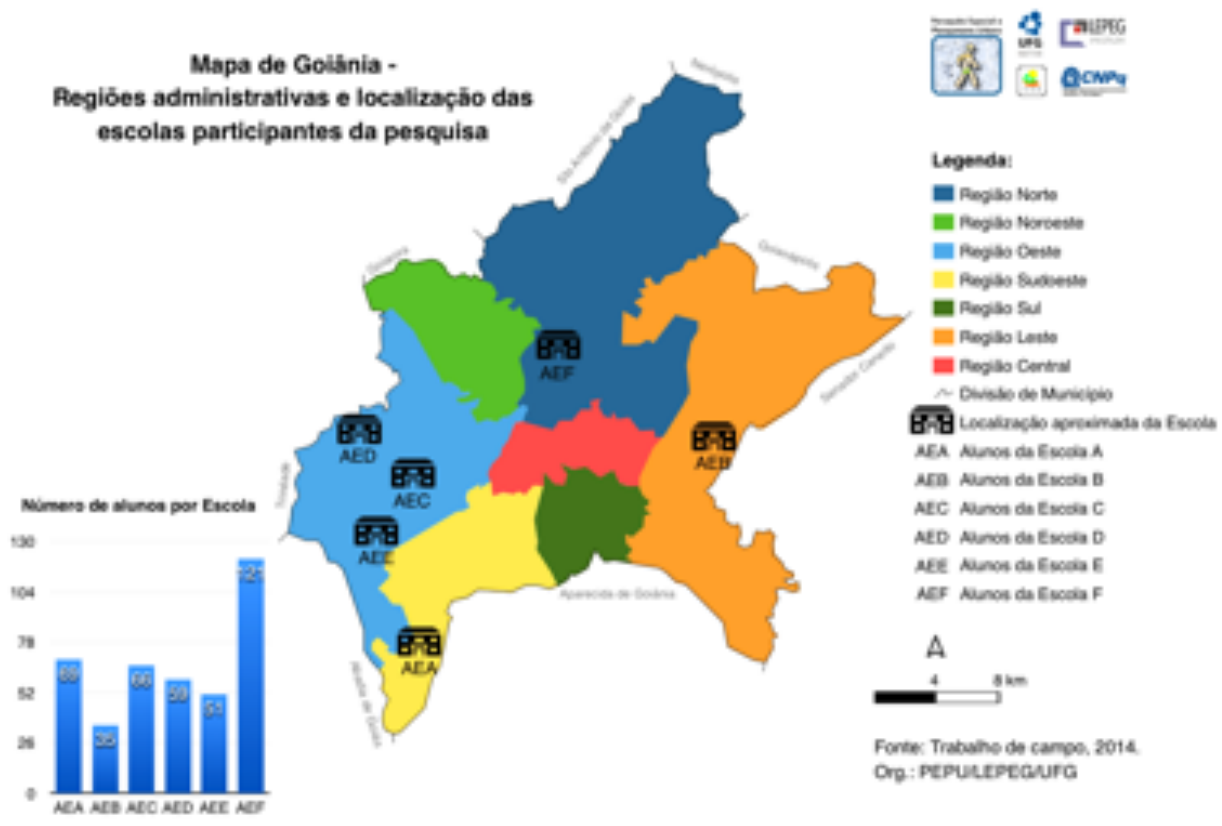

Figura 01. Mapa de Goiânia com a localização das esco las participantes da pesquisa. Org.: PEPU/LEPEG/UFG, 2014. 
Esse mapa (Figura 01) nos permite reconhecer que, com base nos critérios de seleção das escolas, nosso estudo se voltou para as áreas periféricas da cidade, tanto espacial como social. Após esta etapa, realizamos o contato com todas as escolas, via direção, solicitando a autorização dessas instituições para que pudéssemos realizar a pesquisa com os alunos do $3^{\circ}$ ano do Ensino Médio. Além disso, os professores de Geografia dessas escolas foram consultados para permitir que suas aulas se tornassem 0 espaço de realização das etapas da pesquisa.

Após a liberação das escolas para o desenvolvimento da pesquisa organizamos o cronograma de construção e realização das etapas do trabalho de campo, como pode ser observado na Figura 02:

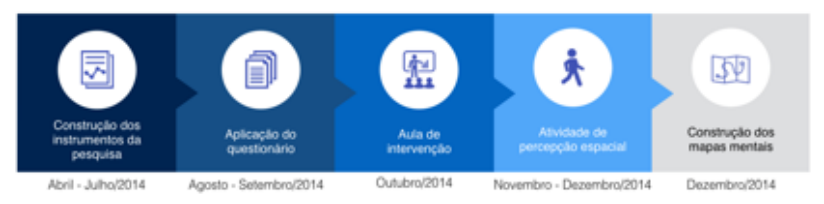

Figura 02. Cronograma das etapas do trabalho de campo. Org.: PEPU/LEPEG/UFG, 2014.

Todo este trabalho gerou um número significativo de dados que nos permitiram construir gráficos e tabelas. Porém, neste artigo selecionamos alguns dados que já foram analisados pela equipe a partir do questionário e que nos ajudam a compreender a percepção dos estudantes sobre a cidade, tendo por referência seu planejamento e suas implicações na prática cotidiana do ir e vir caminhando para à escola.

\section{0 trajeto casa-escola: a percepção dos jovens estudantes sobre o planejamento urbano}

Tendo por base esse estudo, apresentaremos a seguir alguns dados preliminares que nos ajudam a compreender a percepção dos alunos do Ensino Médio de Goiânia a respeito do planejamento urbano. Para isso, selecionamos quatro itens que estavam presentes no questionário e que contribuem para indicar alguns contextos que são valorados pelos estudantes em suas análises espaciais sobre a cidade, a saber: 1) o percentual de alunos que fazem o percurso casa-escola caminhando; 2) o tempo médio que o estudante realiza este trajeto a pé; 3) a avaliação dos alunos em relação à qualidade das calçadas; e 4) a percepção dos jovens estudantes sobre o nível de segurança ao longo deste percurso. Por fim, apresentamos um quadro síntese produzido pela equipe que reúne outros elementos e contextos que foram identificados a partir da pesquisa de campo e dos instrumentos de coleta de dados.
Entendemos que é na experiência in loco com a cidade, na vivência direta com os objetos ou contextos reais da infraestrutura urbana é que poderia nos dar uma leitura mais pertinente sobre a cidade. Desse modo, mesmo tendo um universo de 401 alunos que responderam nosso questionário, definimos que os dados validados para as análises seriam apenas dos estudantes que fazem o trajeto casa-escola a pé. Esta ideia está diretamente relacionada a abordagem de Certeau (2014, p. 164), ao dizer que,

Vendo as coisas no nível mais elementar, ele (o pedestre) tem com efeito uma tríplice função "enunciativa": é um processo de apropriação do sistema topográfico [...]; é uma realização espacial do lugar [...]; implica relações entre posições diferenciadas $[\ldots]$.

Seguindo esta concepção, entendemos que a leitura desses estudantes seria mais pertinente se os mesmos realizassem efetivamente a prática da caminhada para observar, analisar e avaliar os elementos e objetos da infraestrutura urbana que podem potencializar o direito de ir e vir no percurso casa-escola. De acordo com este critério, os mapas e dados a seguir são provenientes das respostas de 262 alunos que nos informaram no questionário que são caminhantes no trajeto casa-escola. Consideramos esse número significativo por representar $65 \%$ dos alunos investigados e nos indicar que a prática da caminhada pela cidade é uma tarefa cotidiana para os estudantes, por isso as políticas e as ações de planejamento urbano precisam valorizar e potencializar esta mobilidade.

Outro elemento que consideramos interessante foi analisar o tempo médio deste percurso casa-escola realizado a pé ou de bicicleta pelos alunos (Figura 04). Por mais que valorizemos a prática da caminhada, é fundamental observarmos quanto tempo o estudante utiliza para fazer este trajeto. Nosso objetivo foi de reconhecer se os alunos moravam nas áreas de entorno de suas respectivas escolas, possibilitando uma vivência mais próxima ao bairro. Além disso, consideramos que uma grande distância da residência até a escola acaba por desestimular o exercício da caminhada, diante do tempo que se utiliza. Por isso, é de suma importância que as escolas estejam bem distribuídas na cidade, para atender às comunidades numa relação de maior proximidade e, assim, reconhecer também as demandas dessa população numa perspectiva de tornar os exemplos e desafios presentes no espaço urbano elementos para dialogar com o ensino de Geografia.

Esta perspectiva atende ao que Cavalcanti (2008) nos destaca sobre o estudo da cidade na escola.

A cidade assim abordada não é trabalhada somente como forma física, mas como materialização de modos de vida, como um espaço simbólico, e seu estudo pretende desenvolver no aluno a compreensão dos modos de vida da sociedade contemporânea, e do seu cotidiano em particular, que resultam em espacialidades determinadas e que são condicionados por elas. Além disso, 
esse estudo contribui para o desenvolvimento de habilidade necessárias aos deslocamentos do aluno, seja em espaços mais imediatos de seu cotidiano, sejam em espaços mais complexos, habilidade que são fundamentais, mesmo que não suficientes, para o usufruto pleno do direito à cidade. (p. 58).

Diante desses contextos, o mapa da Figura 04 apresenta o tempo médio dos alunos no percurso casa-escola, o qual indica que a maior parte dos estudantes (60\%) reside nas proximidades da escola ao fazer este trajeto em até 15 minutos.

Em relação aos elementos específicos da infraestrutura urbana, questionamos os alunos sobre a avaliação a respeito da qualidade das calçadas ao longo do percurso casa-escola. Neste caso, consideramos que essa análise dos estudantes é de grande relevância por valorizar a prática da caminhada e como espaço destinado aos pedestres, pois uma calçada que cumpre com sua função oferece ao indivíduo o direito de percorrer seu trajeto com segurança e delimita sua área no espaço público. Em nosso estudo identificamos que este é um desafio ainda a ser superado pelos órgãos municipais da cidade de Goiânia que fiscalizam e regularizam a qualidade das calçadas. 0 mapa da Figura 04 apresenta a avaliação dos alunos e nos indica as péssimas condições das calçadas.

Vale destacar que ao questionarmos os alunos sobre a qualidade das calçadas houve um debate durante a aula de intervenção no que diz respeito à responsabilidade da prefeitura em melhorar essa infraestrutura, valorizando e respeitando os pedestres. Portanto, ao propormos que os alunos analisassem seus espaços cotidianos foi possível que os mesmos começassem a construir uma leitura mais crítica sobre a cidade e a entender os problemas que ocorrem no planejamento urbano.

Associado a este debate outro ponto que gerou muita discussão pelos estudantes no momento de responder o questionário foi sobre o nível de segurança deles ao longo do trajeto realizado a pé ou de bicicleta. O mapa da Figura 05 evidencia que a percepção dos alunos é de muita insegurança neste percurso.

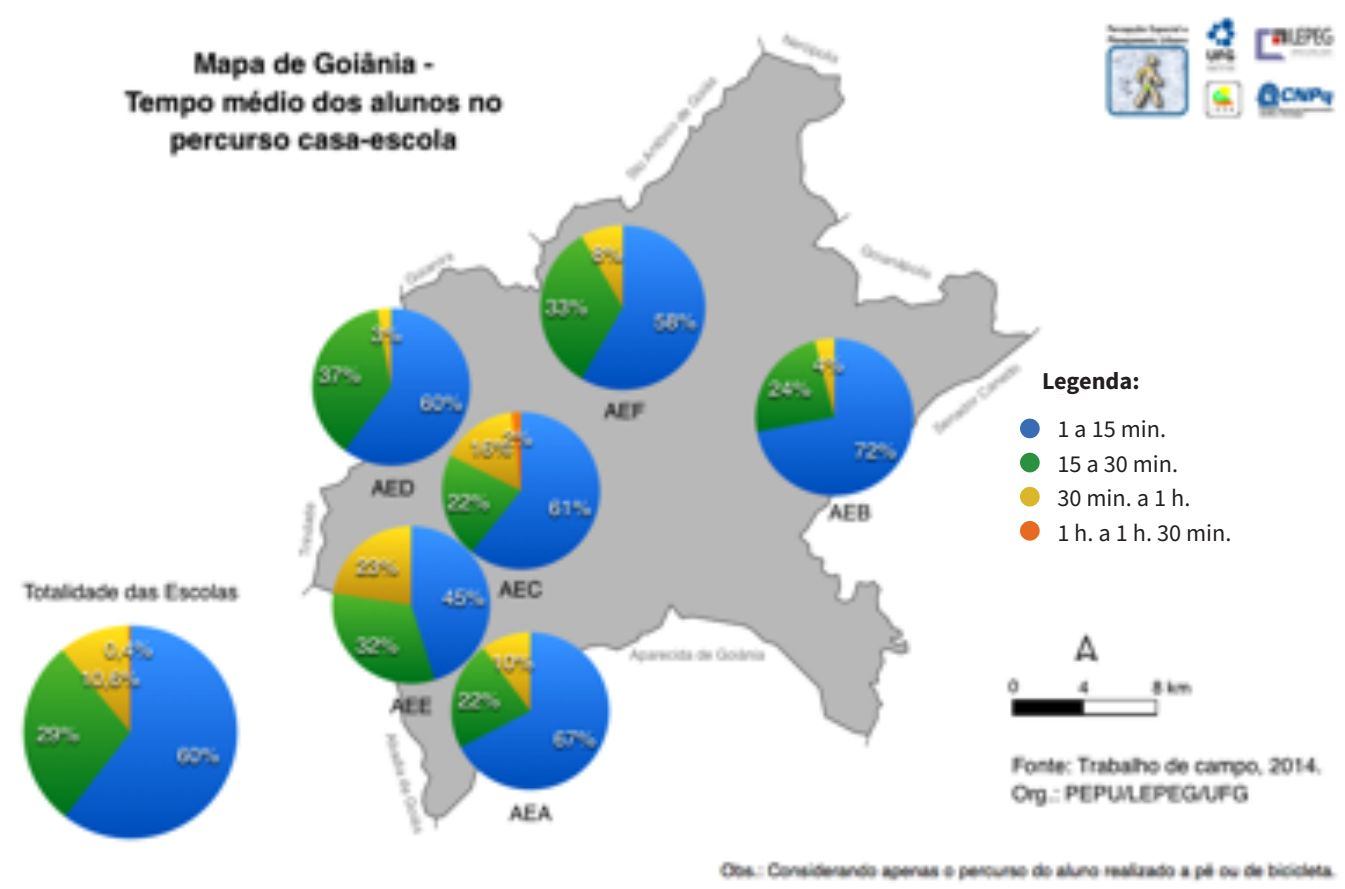

Figura 03. Mapa de Goiânia - tempo médio dos alunos no percurso casa-escola. Org.: PEPU/LEPEG/UFG, 2015. 
Mesmo sendo nítida a indicação negativa dos alunos em relação ao nível de segurança no caminho casa-escola, temos que reconhecer que se trata de uma percepção. Portanto, esta é construída coletivamente por meio de diversos contextos ou leituras (Lynch, 2006). É forte em nossa sociedade atual a valorização da violência e sua divulgação pelos meios de comunicação. Isso não significa que os fatos não possam ser noticiados, mas torna-se recorrente por parte das diversas mídias a valorização dos atos de violência em relação a outros contextos. Portanto, sem querer negar a existência de furtos, roubos, assaltos, etc., vivenciados pelos próprios alunos, esses dados nos revelam a necessidade de discutir nas aulas de Geografia o que vem a ser segurança e como essa ideia é construída nos dias atuais.

Esse debate dialoga com as ideias de Haesbaert (2014) ao dizer que,

"Segurança", em suas múltiplas matizes, pode-se afirmar, é um termo da moda. Das mudanças climáticas e as estratégias militares globais de uma potência como os Estados Unidos às táticas da vida cotidiana de cada um de nós, a segurança está na ordem do dia. Ações políticas, concepções ideológicas, e amplos setores da economia são promovidos em torno da questão. Todos querem "mais segurança", praticamente todos estão envolvidos pelo temos da "insegurança”. (p. 153).

Mesmo sendo um recorte de todos os dados que já foram organizados e previamente analisados, observamos que os alunos tiveram condições de exercer suas leituras e análises a respeito da cidade sob a ótica do planejamento urbano. Além disso, houve uma forte associação dos temas tratados no questionário e na atividade de percepção espacial (percurso em áreas de entorno da escola) com o ensino de Geografia, valorizando este saber disciplinar e escolar como um conhecimento que contribui para uma leitura crítica do cotidiano.

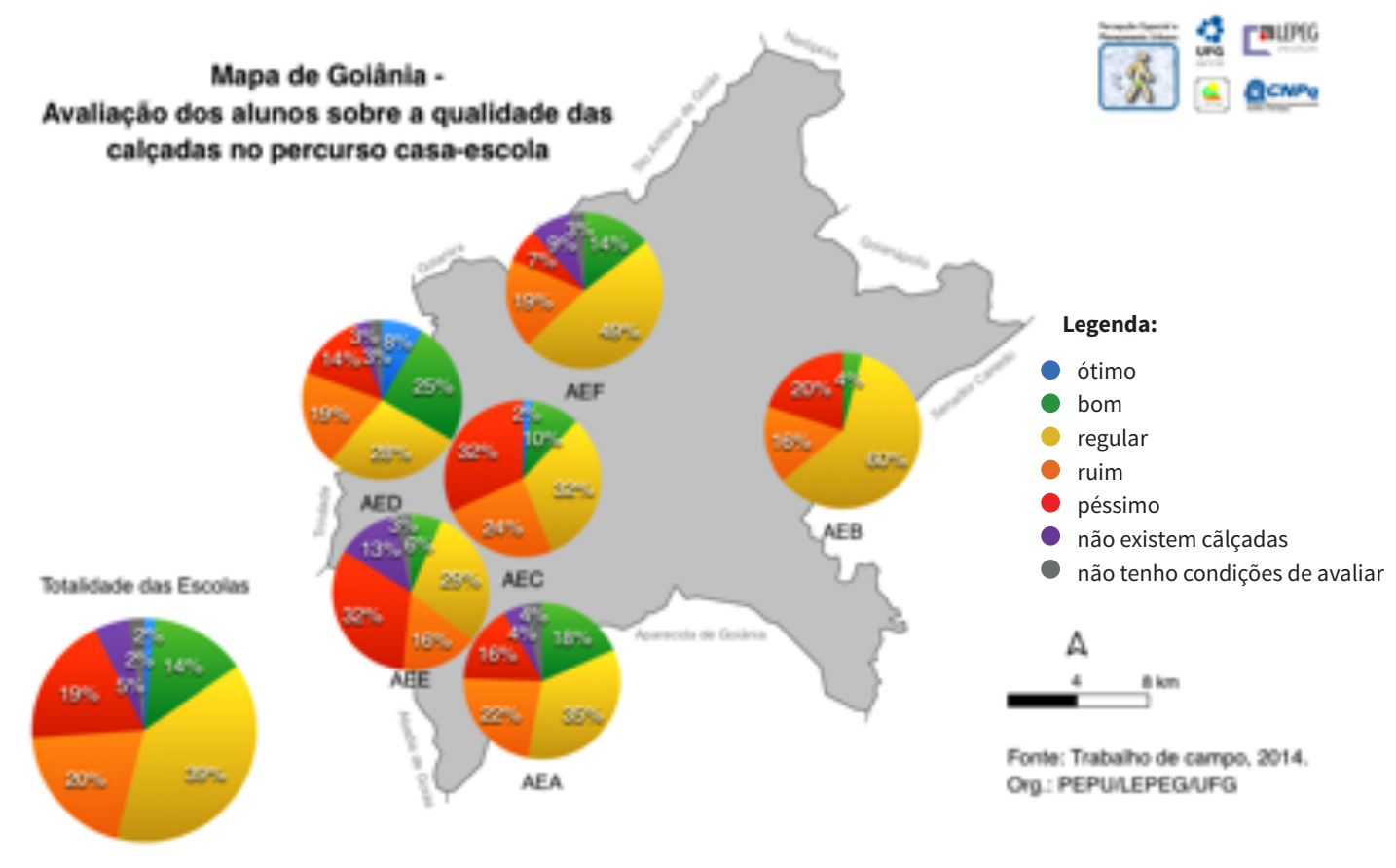

Figura 04. Mapa de Goiânia - avaliação dos alunos sobre a qualidade das calçadas no percurso casa-escola. Org.: PEPU/LEPEG/UFG, 2015. 


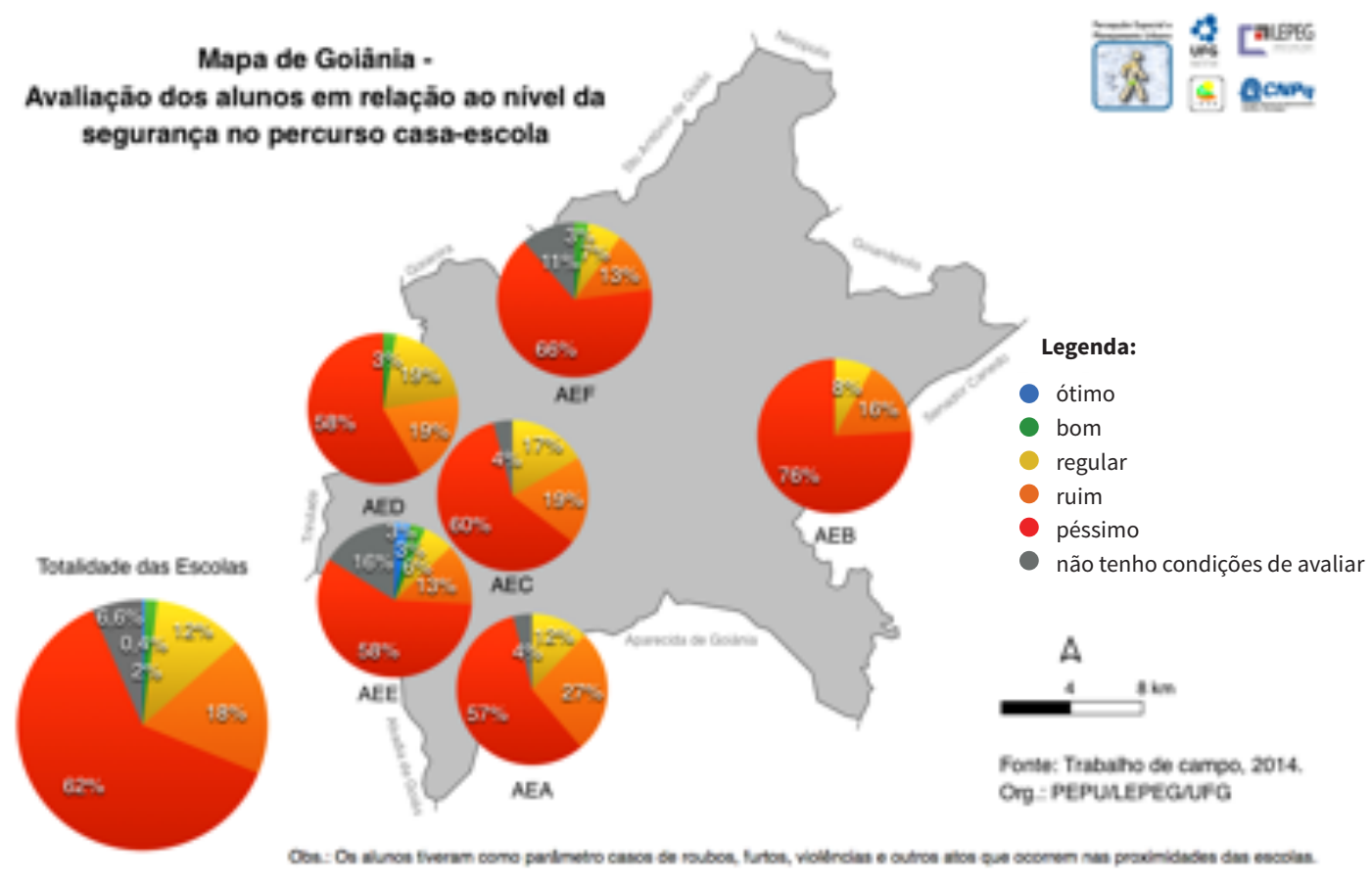

Figura 05. Mapa de Goiânia - avaliação dos alunos em relação ao nível de segurança no percurso casa-escola. Org.: PEPU/LEPEG/UFG, 2015.

\section{Palavras finais}

Como destacamos no início deste texto, selecionamos aqui apenas alguns dados já analisados pela equipe, mas que nos permitem reconhecer as demandas por melhorias no planejamento urbano da cidade de Goiânia na perspectiva dos jovens estudantes que percorrem cotidianamente o trajeto casa-escola. Contudo, essa análise torna-se mais ampla se integrarmos as percepções dos alunos a partir de outros itens presentes no questionário que nos ajudaram a construir um quadro síntese e que indicam outras urgências, como pode ser observado na Figura 06.

Esses dados apresentam os desafios presentes na cidade de Goiânia para tornar o planejamento urbano mais próximo das demandas dos sujeitos que participam ativamente desse espaço. Ressaltamos, ainda, que uma das ações desta investigação é apresentar à prefeitura de Goiânia os resultados finais desse trabalho, possibilitando que os órgãos competentes possam reconhecer a percepção dos jovens estudantes sobre a cidade e potencializar mudanças necessárias para tornar o espaço urbano mais pleno de direitos.

Portanto, ao propor a cidade com uma escala de análise, a partir dos elementos e contextos presentes no planejamento urbano e utilizando o próprio aluno como leitor crítico desse espaço, tendo por base sua percepção, temos condições de desvelar os problemas que estão materializados, mas que, muitas vezes, o estudante tem dificuldade de reconhecer pelo fato da escola e, principalmente, das aulas de Geografia não permitirem um olhar mais atendo. É nesta perspectiva que entendemos a pertinência de nosso estudo. 


\section{Referências}

Arrais, T. A.,. (2006). Acionando territórios: a mobilidade na região metropolitana de Goiânia e em aparecida de Goiânia. Boletim Goiano de Geografia,26 (1), pp. 91-114.

Cavalcanti, L. de S.,, (2008). A Geografia escolar e a cidade: ensaios sobre o ensino de Geografia para a vida urbana cotidiana. Campinas: Papirus.

Claval, P., (2002). A revolução pós-funcionalista e as concepções atuais da Geografia. Em: F. Mendoça \& S. Kozel (orgs.). Elementos de epistemologia da geografia contemporânea. (pp.11-43)Curitiba: Ed. da UFPR.

Certeu, M. de, (2014). A invenção do cotidiano: 1. Artes de fazer. (21ª ed.). Petrópolis: Vozes.

Instituto Brasileiro de Geografia e Estatística (IBGE). (2010). Censo Demográfico 2010: características urbanísticas do entorno dos domicílios. Recuperado em 18 de junho de 2012 de: <http://www.ibge.gov.br/home/presidencia/noticias/ noticia_impressao.php?id_noticia $=2140>$.

Haesbaert, R., (2014). Viver no limite: território e multi/transterritorialidade em tempos de in-segurança e contenção. Rio de Janeiro: Bertrand Brasil.

Lynch, K., (2006). A imagem da cidade. São Paulo: Martins Fontes.

Lefebvre, H., (2001). O direito à cidade. São Paulo: Centauro. 